\title{
An Abrasion Wear Model of Rotary Shear Comminution of Biomass Feedstock
}

Applied Materials Division 


\begin{abstract}
About Argonne National Laboratory
Argonne is a U.S. Department of Energy laboratory managed by UChicago Argonne, LLC under contract DE-AC02-06CH11357. The Laboratory's main facility is outside Chicago, at 9700 South Cass Avenue, Lemont, Illinois 60439. For information about Argonne and its pioneering science and technology programs, see www.anl.gov.
\end{abstract}

\title{
DOCUMENT AVAILABILITY
}

Online Access: U.S. Department of Energy (DOE) reports produced after 1991 and a growing number of pre-1991 documents are available free at OSTI.GOV (http://www.osti.gov/),

a service of the US Dept. of Energy's Office of Scientific and Technical Information.

Reports not in digital format may be purchased by the public from the National Technical Information Service (NTIS):

U.S. Department of Commerce

National Technical Information Service

5301 Shawnee Road

Alexandria, VA 22312

www.ntis.gov

Phone: (800) 553-NTIS (6847) or (703) 605-6000

Fax: (703) 605-6900

Email: orders@ntis.gov

Reports not in digital format are available to DOE and DOE contractors from the Office of Scientific and Technical Information (OSTI):

U.S. Department of Energy

Office of Scientific and Technical Information

P.O. Box 62

Oak Ridge, TN 37831-0062

www.osti.gov

Phone: (865) 576-8401

Fax: (865) 576-5728

Email: reports@osti.gov

\section{Disclaimer}

This report was prepared as an account of work sponsored by an agency of the United States Government. Neither the United States Government nor any agency thereof, nor UChicago Argonne, LLC, nor any of their employees or officers, makes any warranty, express or implied, or assumes any legal liability or responsibility for the accuracy, completeness, or usefulness of any information, apparatus, product, or process disclosed, or represents that its use would not infringe privately owned rights. Reference herein to any specific commercial product, process, or service by trade name, trademark, manufacturer, or otherwise, does not necessarily constitute or imply its endorsement, recommendation, or favoring by the United States Government or any agency thereof. The views and opinions of document authors expressed herein do not necessarily state or reflect those of the United States Government or any agency thereof, Argonne National Laboratory, or UChicago Argonne, LLC. 
ANL/AMD-21/2

\section{An Abrasion Wear Model of Rotary Shear Comminution of Biomass Feedstock}

by

George Fenske and Oyelayo Ajayi

Applied Materials Division, Argonne National Laboratory

August 2021 



\section{CONTENTS}

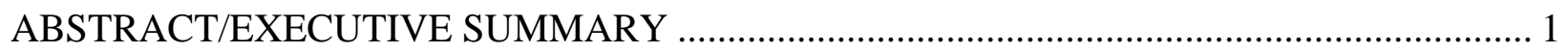

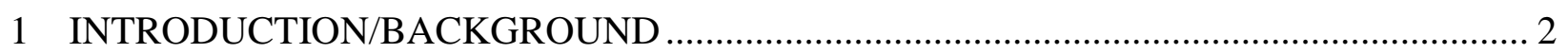

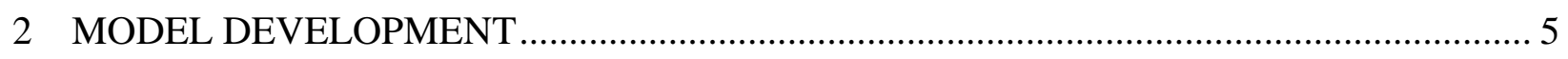

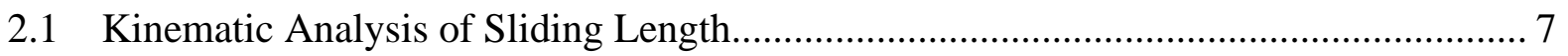

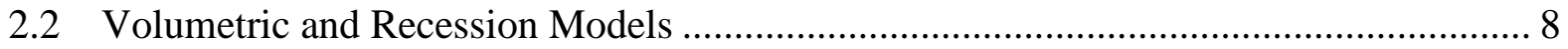

3 APPLICATION OF MODEL TO PREDICT CUTTER WEAR ……………....................... 10

3.1 Case 1 - Impact of Ash Content and Particle Size ..................................................... 11

3.2 Case 2 - Impact of Particle Shape and Wear Constant................................................ 12

3.3 Case 3 - Impact of Material Property (Hardness) ........................................................ 14

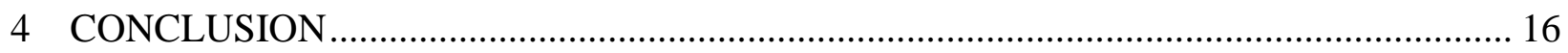

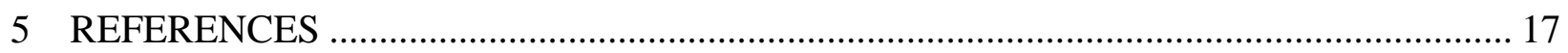

\section{FIGURES}

1 Major unit operations used in the comminution of biomass feedstocks ................................ 2

2 Photos of Forest Concepts Crumbler ${ }^{\circledR}$ shearmill and cutting teeth. ........................................... 3

3 Optical images of cutter teeth: left - as-new; center - after run-in; and right - prior to failure.

4 CAD representation of cutters mounted on parallel overlapping shafts dragging organic and inorganic material through the shearing zone.

5 Illustration of chemical mechanical polishing processes used by industry to polish components.

6 Illustration of the volume of material worn as a particle of diameter D slides a distance L across the surface. "h" represents the indentation depth, while "d" represents the diameter of the indentation as measured on the original surface........................ 5

7 Predicted elastic/plastic behavior of particle-chip and particle-cutter indentation.................... 6

8 Calculated elastic and plastic indentation depths as functions of applied load for particle-cutter and particle-chip interactions. ........................................................................ 6

9 End-on layout of cutters for Forest Concept rotary shear.................................................... 7

10 Relative speed as a function of radial position and off-axis position. ...................................... 7

11 Differential sliding distance as a function of rotational angle and radial position. ................... 8

12 Total relative sliding distance as a function of radial position in the shear zone. .................... 8

13 Schematic of incremental wear volume on the side of a rotary shear cutter. ........................... 9 


\section{FIGURES (CONT.)}

14 Predicted face recession after 1-day operation as a function of radial position for different levels of ash content and particle size. ..................................................... 12

15 Simple illustration of an oval particle trapped between two surfaces. ................................ 12

16 Edge recession as a function of radial position after 1-day operation for spherical particles and oval particles.

17 Edge recession as a function of radial position after 1 -day operation for $\eta=1, K=1$, and $\eta=1, K=0.1$.

18 Edge recession as a function of radial position after 1-day operation for baseline and modified.

19 Edge recession as a function of radial position after 1-day operation for baseline, baseline heat treated to $\mathrm{Hv}=650$, and iron borided.

20 Comparison of predicted recession as a function of radial position after 24 hours running at $300 \mathrm{rpm}$ for baseline and combined run.

\section{TABLES}

1 Material attributes and operating parameters used to model abrasive wear of rotary shear cutter surfaces . 10

2 Calculated particle densities for different particle sizes and ash content. 


\begin{abstract}
EXECUTIVE SUMMARY
The research team formulated a workable analytical abrasion model that relates critical rotary shear process parameters (shear geometry and rotational speed) to critical material attributes of inorganic mineral species in feedstock (density, size, and aspect ratio) and substrate (hardness and elastic modulus) that enabled us to model the wear of shear cutters in a rotary shear milling system developed by Forest Concepts. We compared results of the model to experimental observations of the shape of rotary shear cutters used in a Forest Concept Crumbler® shearmill. Results showed good agreement between the predicted and measured shape of a worn cutter; thus, a quality-by-design (QbD) approach can be developed to predict component reliability based on scientific engineering principles in lieu of trial-and-error approaches.
\end{abstract}




\section{INTRODUCTION/BACKGROUND}

There is considerable interest worldwide in developing processes to transform nonfood sources of biomass into bioproducts, biofuels, and bioenergy. The U.S. Department of Energy's Bioenergy Technologies Office supports activities to develop innovative technologies for converting biomass into usable products, fuels, and energy, including its initiatives in feedstock supply and logistics (FSL), algal biofuels, sustainability, analysis, and conversion technologies [1]. Recognizing the importance of pretreatment of biomass feedstocks on the development of value-added products [2-4], the Feedstock Conversion Interface Consortium (FCIC; https://fcic.inl.gov) develops first principles-based knowledge and tools to understand the effects of biomass properties and process variability on pretreatment operations.

Pretreatment of biomass feedstocks is an essential step in changing the structure of lignocellulosic fractions into a state that responds to enzymatic hydrolysis. Pretreatment processes involve a number of unit operations (defined as process steps leading to physical change or chemical transformation) that may require milling, grinding, cutting, and/or mechanical transport of the feedstocks from one stage to another. Because of the nature of mechanical interactions between feedstock (and ash) and surfaces of materials of construction, wear can occur and limit the reliability and functionality/performance of critical unit operations.

Preprocessing-related unit operations can also result in wear of components [5]. These operations include bale processing (e.g., deconstruction/shredding of corn stover bound up into square/rectangular bales or round bales weighing approximately half a ton) and size reduction operations to yield loose, free-flowing biomass that can be readily treated by downstream pretreatment and conversion/digestion processes. Additional processing steps are often used to remove rock, gravel, sand, and nonferrous metallic contaminants and to classify/separate the biomass by size and anatomical fractions prior to size reduction operations [6]. Figure 1 illustrates the flow diagram of major preprocessing operations used in the comminution of biomass feedstock. The operations shaded in blue represent those sensitive to mechanical wear phenomena that can degrade performance and productivity.

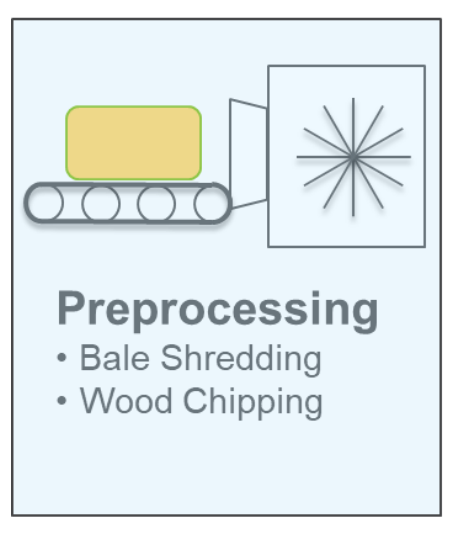

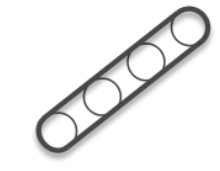

Separation \& Classification

- Contaminants

- Anatomical fractionation
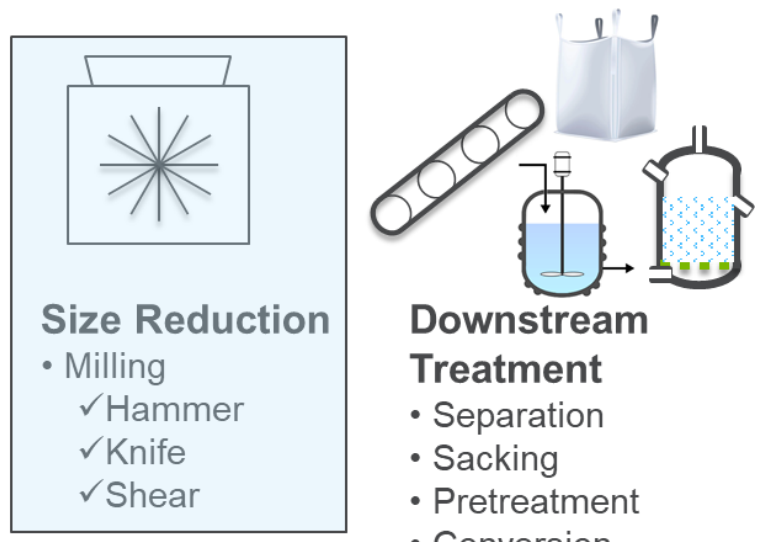

Downstream

Treatment

- Separation

- Sacking

- Pretreatment

- Conversion

FIGURE 1 Major unit operations used in the comminution of biomass feedstocks (Source: adapted from [7] with permission.) 
One of the approaches under consideration for size-reduction is shearing, more specifically, rotary shearing of wood chips (or corn stover) down to sizes required for downstream treatment. Forest Concepts has developed a rotary shear unit (Crumbler@) that is under development for biomass conversion [8]. Figure 2 shows a photo of a Crumbler® shearmill being fed with wood chips (left), with a close up of the cutters (right) illustrating wear on the teeth that pull the chips through the milling zone.
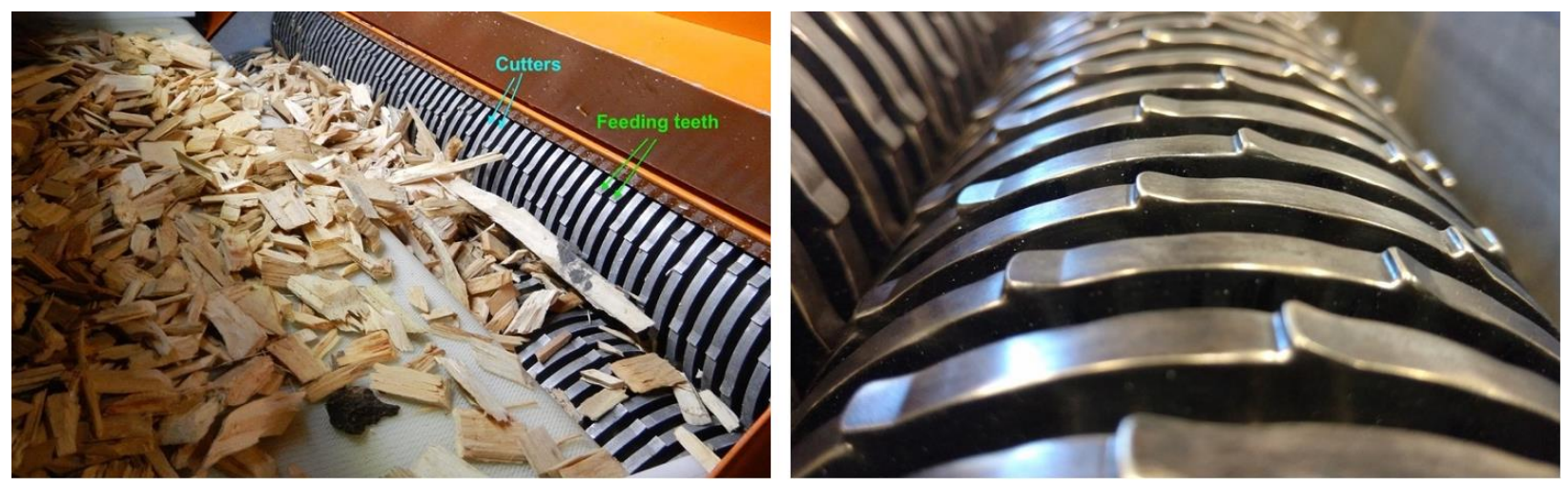

FIGURE 2 Photos of Forest Concepts Crumbler® shearmill (left) and cutting teeth (right) [9].

Experience operating the Crumbler® indicates significant benefits with regard to producing a narrow particle size distribution of biomass chips that exhibit high flowability and high tolerance of high moisture variability. However, abrasive wear on the feeding teeth and clearing plates when processing dirty biomass (intrinsic and extrinsic mineral debris) can significantly reduce desired cutter life. Figure 3 shows examples of the type of wear that occurs on the cutter teeth. The teeth are initially sharp (left) and can grab and pull the wood chips down into the zone where shearing occurs. Extrinsic, inorganic ash transported along with the biomass is carried through the shearing zone and can abrade the critical surfaces, resulting in a loss of material and change in tooth shape (center and right). The tooth on the left is sharp and can engage the chips, whereas the tooth on the right has been rounded and has difficulty engaging the wood chips. As a result of the tooth wear, the throughput of the unit is degraded, necessitating replacement of the cutter sets.
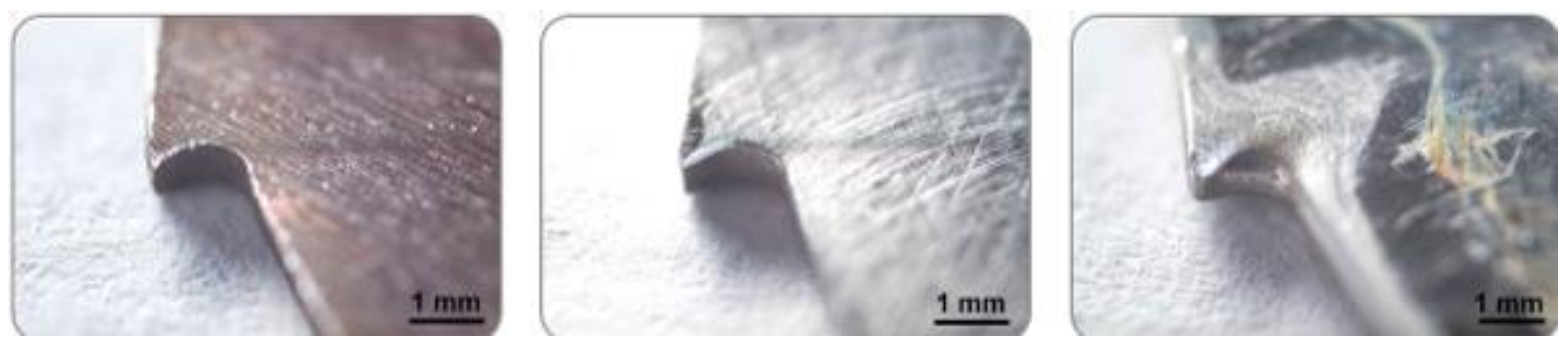

FIGURE 3 Optical images of cutter teeth: left - as-new; center - after run-in; and right prior to failure. [10] 
Analysis of worn cutter blades [9] indicate that abrasion is the active wear process occurring at the cutters. Abrasion is a complex phenomenon whose impacts are dependent (1) on the nature of the material (biomass feedstock and entrained ash) causing the wear, (2) the nature of the material undergoing wear (material and mechanical properties of materials of construction), and (3) operating/process parameters (speed, temperature, loads, and geometry).

The current approach to address wear is often based on trial-and-error testing of materials that are used in mature process applications (e.g., paper and pulp processing). While this approach can be a good start, the operating conditions and variability of feedstocks are often sufficiently different from the original, intended application that unanticipated reliability and durability issues result. The high level of ash in biomass is a good example: the ash content is considerably greater than the levels allowed in paper and pulp feedstocks.

While employing a trial-and-error approach has its uses, acquiring an ability to predict wear based on critical material attributes and critical process parameters has great potential for more effective design and engineering of unit operation processes.

The results presented in this report describe efforts to develop and apply a mechanistic model of wear based on physical mechanisms involved in abrasion to predict wear of the Forest Concept Crumbler® rotary shear. Figure 4 shows a computer-aided design (CAD) drawing of a Forest Concept rotary shear. The shear consists of cutters mounted on two counter-rotating shafts. The shafts are parallel to one another and spaced such that the

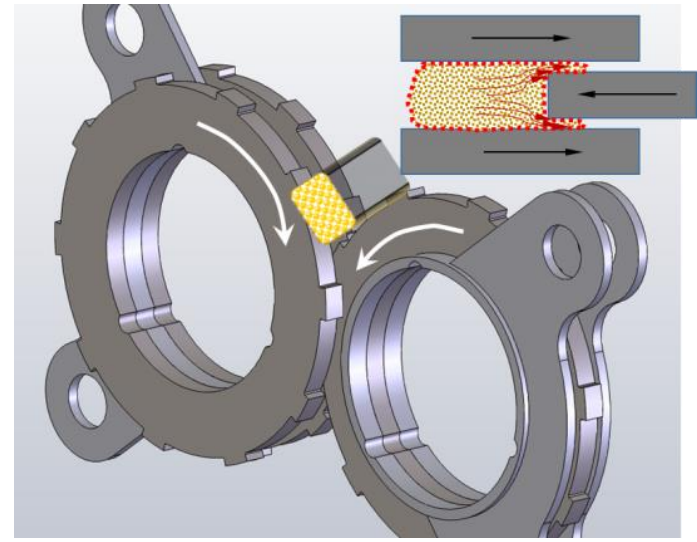

FIGURE 4 CAD representation of cutters mounted on parallel overlapping shafts dragging organic and inorganic material through the shearing zone. cutters overlap/mesh. The chips, along with hard inorganic ash and dirt, are transported through the region where adjacent cutters overlap. Hard inorganic particles, either loose or embedded in the surface of the softer biomass chips, can penetrate into the harder cutter and plastically deform, fracture, or fatigue it near surface regions, resulting in wear and loss of material. The process is illustrated in Figure 5, where hard and

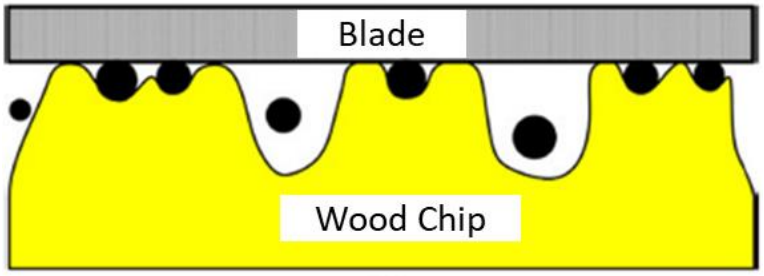

FIGURE 5 Illustration of chemical mechanical polishing processes used by industry to polish components. abrasive materials are embedded/trapped on wood chips that slide across the faces of the cutter blades. The process illustrated in Figure 5 is very similar to chemical mechanical polishing (CMP), a process used in industrial settings to finish components. Thus, the model we have developed is based on approaches used to model the wear of silicon wafers polished by CMP $[11,12]$. 


\section{MODEL DEVELOPMENT}

The model begins with the development of a constitutive equation for abrasive wear to calculate the volume of material lost, $\Delta \mathrm{V}$, as a particle slides across a surface. The model is illustrated in Figure 6, which depicts a particle of diameter $D$, subjected to a load, $W$, that slides a distance $L$ across the surface. Because of the applied load, the particle elastically (or plastically) penetrates a distance $h$ into the surface. The amount of material worn is thus a semicircular trough, which geometrically is given as [13]:

$$
\operatorname{Vol}\left(m^{3}\right)=\frac{\left[(D / 2)^{2}\right]}{2}(\alpha-\sin \alpha) x L
$$

where $\alpha$ is the central angle as shown in Figure 6 . The central angle, $\alpha$, can be obtained geometrically

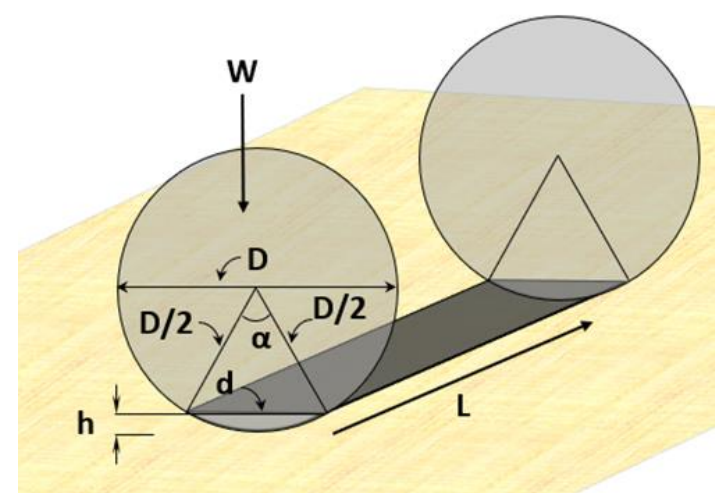

FIGURE 6 Illustration of the volume of material worn as a particle of diameter $D$ slides a distance $L$ across the surface. " $h$ " represents the indentation depth, while "d" represents the diameter of the indentation as measured on the original surface. as:

$$
(D / 2) \cos (\alpha / 2)=(D / 2)-h
$$

or as:

$$
\alpha=2 \operatorname{acos}[1-2 h / D]
$$

The indentation depth, $h$, depends on the nature of the deformation process. Under light loads $(W)$, the deformation will be elastic in nature. At some critical load, plastic flow will begin to take place below the surface, resulting in elastoplastic behavior. At even higher loads, the deformation is fully plastic. We have employed a Hertzian treatment to model $h$ as a function of load, elastic modulus, and particle size for elastic interactions:

$$
W_{e}=\frac{4}{3} E^{*} \sqrt{D / 2} h^{3 / 2}
$$

where $\mathrm{E}^{*}$ is the composite/reduced elastic modulus of the particle and flat:

$$
E^{*}=1 /\left[\frac{1-v_{1}^{2}}{E_{1}}+\frac{1-v_{2}^{2}}{E_{2}}\right]
$$

A plastic deformation treatment is used for plastic interactions:

$$
W_{p}=H * \pi * D * h
$$

where $H$ is the hardness and $h$ is the indentation depth. 
We therefore have two solutions for the indentation depth, a fully elastic solution (eq. 4) or a fully plastic solution (eq. 6). The decision as to which solution to use depends on hardness, elastic modulus, and particle size and load. The approach used by Zhao et al. [11, 12] for CMP was applied to estimate the critical indentation depth, $h_{\mathrm{i}}$, where the deformation behavior transitions from pure elastic to elastoplastic behavior, and the critical depth, $h_{2}$, where the deformation is fully plastic. The equations for $h_{\mathrm{i}}$ and $\mathrm{h}_{2}$ are given as:

$$
\begin{gathered}
h_{i}=\left[3 \pi k H / 4 E^{*}\right]^{2}(D / 2) \\
h_{2}>\left[3 \pi H / 2 E^{*}\right]^{2}(D / 2)>4 h_{i} / k^{2}
\end{gathered}
$$

where $k$ is a mean contact pressure factor that correlates the mean contact pressure for initial yielding to the hardness. Using material properties typical of woody biomass and materials typically used for construction of the cutters, we concluded that the interactions between the inorganic ash particles (representative of silica) and the biomass (pine) and between the particle and the cutter (hardened 1095 steel) are plastic in nature, as illustrated in Figure 7. Predicted values of $h_{i} / D$ for $100-\mu \mathrm{m}$ silica particles pressed against pine and 1095 steel are $3.4 \mathrm{e}-3$ and $4.9 \mathrm{e}-6$,

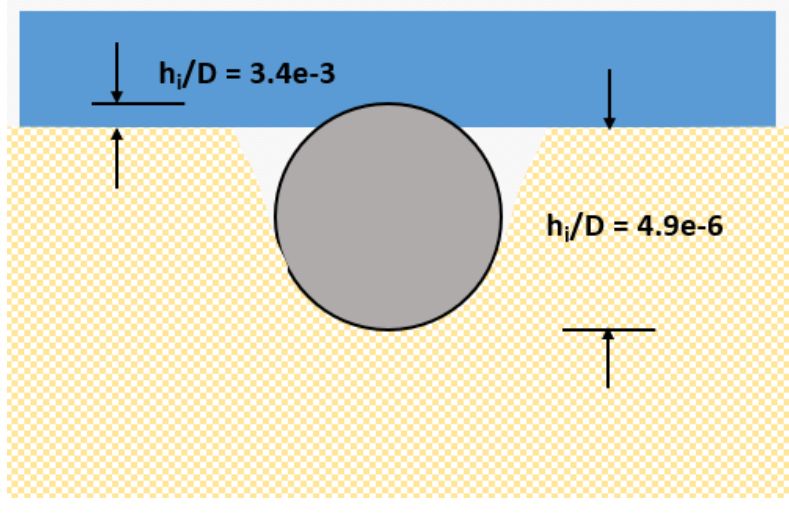

FIGURE 7 Predicted elastic/plastic behavior of particle-chip and particle-cutter indentation. respectively, suggesting that once the particle is indented more than $0.034 \mu \mathrm{m}$ into the cutter or $0.0005 \mu \mathrm{m}$ into the pine, the behavior is elastoplastic/plastic in nature.

Based on the analysis above, we note that at low loads, elastic deformation dominates, whereas at higher loads, plastic deformation dominates, as evident in Figure 8 for particle-cutter and particle-chip interactions. Indentation is dominated by elastic deformation for particle-cutter interactions, whereas plastic deformation dominates for particle-chip interactions.
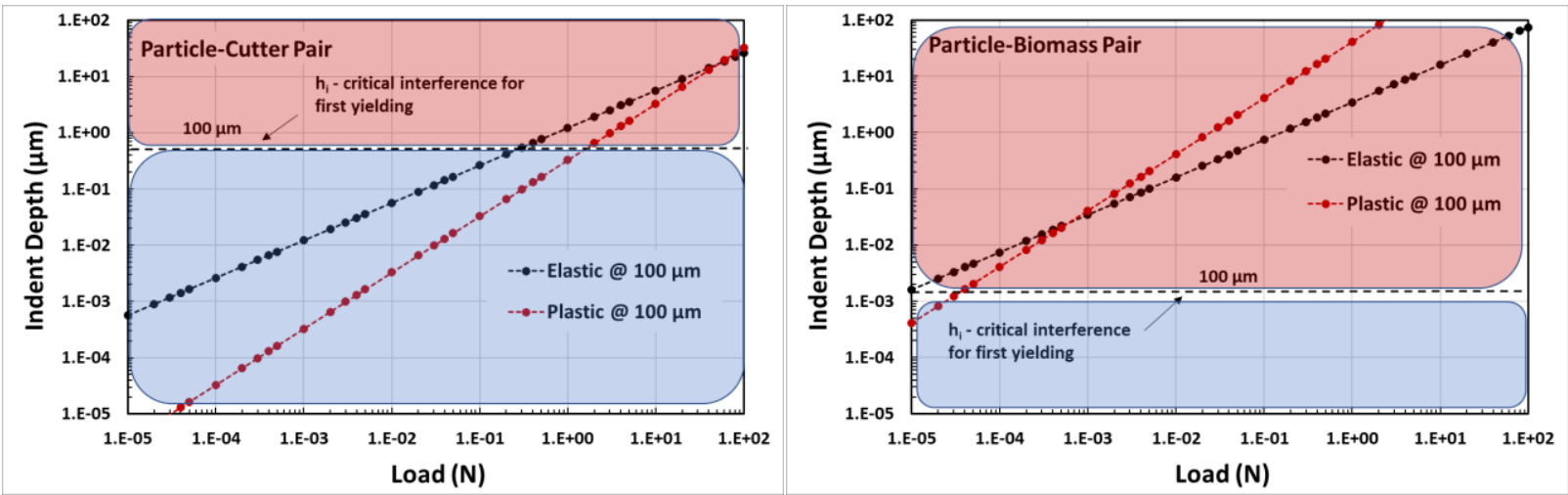

FIGURE 8 Calculated elastic and plastic indentation depths as functions of applied load for particle-cutter (left) and particle-chip (right) interactions. 


\subsection{Kinematic Analysis of Sliding Length}

According to the geometrical calculation of the material dislocated/removed as presented in Equation 1, the volume of material removed is proportional to the cross-sectional area of the semicircular cross-section and the sliding length, $L$. Calculation of the cross-sectional area can be accomplished using Equation 6 coupled with Equations 2 and 3 - given the particle size, hardness, and applied load. Calculation of the sliding distance, $L$, requires analysis of the kinematic motion of the counter-rotating cutters to determine the relative sliding motion between adjacent cutters as a function of radial position on a cutter, cutter dimensions, and shaft-to-shaft spacing.

Figure 9 shows an end-on view of the layout of the cutters on a Crumbler® rotary shear. The cutters approximately $10 \mathrm{~cm}$ in diameter are spaced horizontally such that they overlap and generate a shearing zone where biomass chips are sheared into smaller sizes. Because wear is limited to conditions where there is relative motion between sliding cutters, obtaining information on the relative speed and motion of the cutters as the biomass and abrasive particles move through the shear zone is critical. A

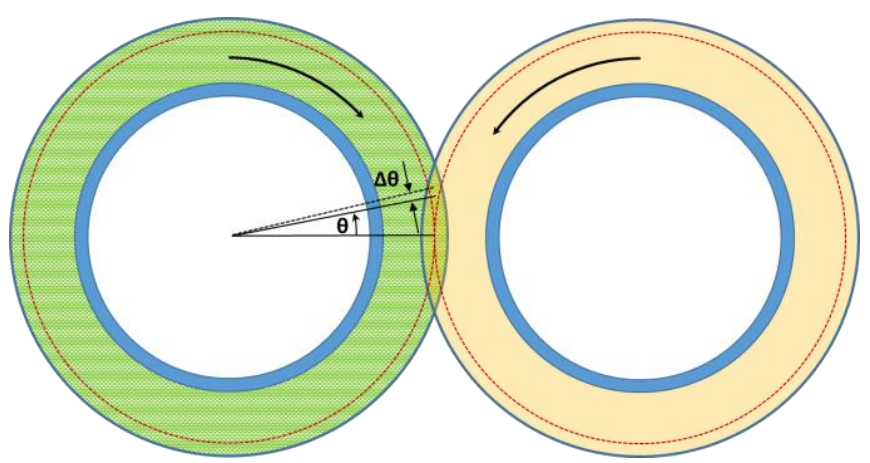

FIGURE 9 End-on layout of cutters for Forest Concept rotary shear. kinematic analysis of the relative speed of a point on one cutter relative to an adjacent point on the partner cutter showed that the speeds that a particle would encounter as it transits through the shear zone would vary significantly depending on position in the zone. This finding is illustrated in Figure 10, which shows the relative speed (not velocity) as a function of radial position on a cutter in the outer $\mathrm{cm}$ of a cutter. The speed is greatest at the outer periphery of the cutters at the points where they first and last engage. The relative speed drops to zero along the horizontal axis connecting the two cutters and proceeds to increase as the pin moves off-axis. At the inner radius of the zone, the relative speed

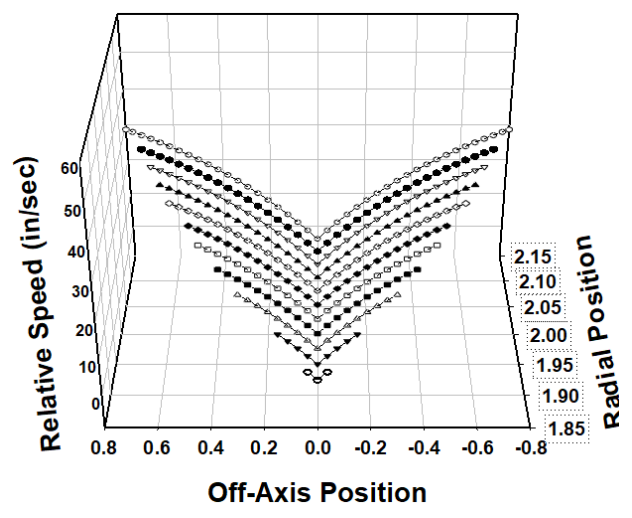

FIGURE 10 Relative speed as a function of radial position and offaxis position. drops to zero.

Using the relative speed analysis, the next step was to integrate the incremental sliding distance to obtain the relative sliding distance as a function of rotation angle, as shown in Figure 11, and eventually to integrate this data with respect to rotation angle to obtain the total relative distance a particle slides as the particle translates through the shear zone, as shown in Figure 12. The curve in Figure 12 is the value of $L$ used in Equation 1. It represents the total relative sliding distance a particle experiences per revolution of a cutter and, as evident in the figure, depend strongly on the radial position. 


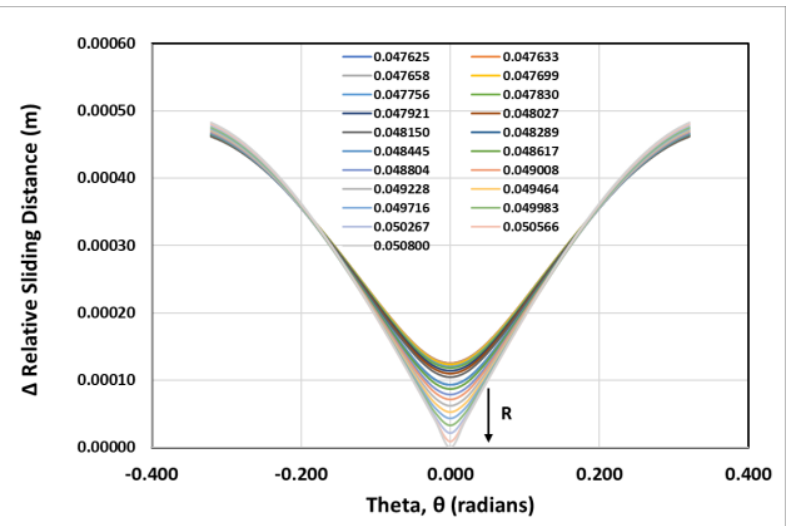

FIGURE 11 Differential sliding distance as a function of rotational angle and radial position.

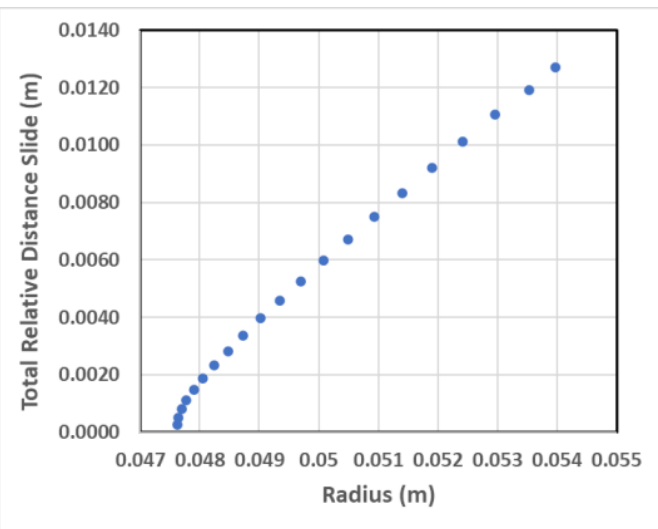

FIGURE 12 Total relative sliding distance as a function of radial position in the shear zone.

\subsection{Volumetric and Recession Models}

Starting with the constitutive equations for abrasive wear (eqs. 1-6), and the kinematic analysis for the sliding distance presented above, the volumetric loss of material per revolution between $r$ and $r+\Delta r$ can be represented as:

$$
\Delta V(\theta \rightarrow \theta+\Delta \theta, r \rightarrow r+\Delta r)=\Delta Q_{\text {abrasion }}\left(m^{3} / \text { particle }\right) * \#(\text { particles })
$$

where: $\Delta \mathrm{Q}_{\text {abrasion }}$ is given by Equation 1,

and: \#(particles) is the number of particles on the surface between $\theta \& \theta+\Delta \theta$ and between $r$ and $r+\Delta r$. see Figure 9 for the definition of the rotational angle is:

$$
\# \text { particles }=\mathcal{X}\left(\text { particles } / \mathrm{m}^{2}\right) * \Delta a
$$

where: $\mathcal{X}$ (particles/ $\mathbf{m}^{2}$ ) is the density of particles residing on the particle/cutter interface and is equal to the inorganic particle density raised to the $\left(2 / 3^{\text {rd }}\right)$ power.

and: $\boldsymbol{\Delta a}$ is the area on a cutter between $\mathrm{r}$ and $\mathrm{r}+\Delta \mathrm{r}$ :

$$
\Delta a=2 \pi r \Delta r
$$

Substituting into eq. 9 , we have:

$$
\Delta V(\theta \rightarrow \theta+\Delta \theta, r \rightarrow r+\Delta r)=\frac{\left[(D / 2)^{2}\right]}{2}(\alpha-\sin \alpha) * L(\Delta \theta, r) * X * 2 \pi r \Delta r
$$

where: $L(\Delta \theta, \mathrm{r})$ is the differential sliding distance shown in Figure 11. Integrating over $\theta$ (where the integration limits depend on $r$ ), we obtain: 


$$
\Delta \mathrm{V}(r \rightarrow r+\Delta r)=\frac{\left[(D / 2)^{2}\right]}{2}(\alpha-\sin \alpha) * \mathcal{L}(r) * X * 2 \pi r \Delta r
$$

where: $\mathcal{L}(\boldsymbol{r})$ is the total relative sliding distance shown in Figure 12.

The schematic in Figure 13 shows the incremental volume of material lost to wear; in this case, the incremental volume, $\Delta v$, is defined as:

$$
\Delta \boldsymbol{v}=\mathbf{2} \pi \mathbf{r} * \Delta \mathbf{r} * \Delta_{\perp}
$$

where: $\Delta_{\perp}$ is the linear recession of the cutter normal to the surface.

By equating $\Delta \boldsymbol{v}$ (Equation 13) to $\Delta \mathrm{V}$ (Equation 12),

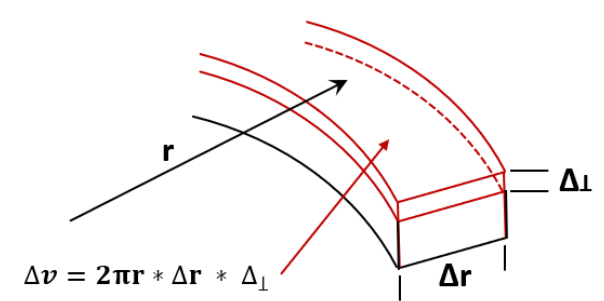

FIGURE 13 Schematic of incremental wear volume on the side of a rotary shear cutter. we obtain:

$$
2 \pi \mathrm{r} \Delta \mathrm{r} \Delta_{\perp}=\frac{\left[(D / 2)^{2}\right]}{2}(\alpha-\sin \alpha) * \mathcal{L}(r) * X * 2 \pi r \Delta r
$$

or:

$$
\Delta_{\perp}=\frac{\left[(D / 2)^{2}\right]}{2}(\alpha-\sin \alpha) * \mathcal{L}(r) * X=\Delta Q_{\text {abrasion }} * X
$$

The variable $\mathcal{X}$ (particles $/ \mathrm{m}^{2}$ ) is determined from several process parameters, including the following:

- Biomass feed rate: $\mathrm{FR}(\mathrm{kg} / \mathrm{sec})$

- Ash content: AC (wt \%)

- Residence time: $\tau(\mathrm{sec})$ dependent on rotational speed and included angle of the shear zone

- Shear zone volume: $\Delta \boldsymbol{v}\left(\mathrm{m}^{3}\right)$

- Particle size D

- Particle density $\quad$ ash density of ash particles (e.g., silica)

- Density of particles Particles $/ \mathrm{m}^{3}$ 


\section{APPLICATION OF MODEL TO PREDICT CUTTER WEAR}

Equation 15 was used to model the wear of cutters used on the Forest Concept Crumbler ${ }^{\circledR}$ rotary shearmill. Two series of Excel spreadsheets were developed to calculate kinematic and wear/recession wear rates. The applications required incorporating information on the following material attributes and operational parameters (listed in Table 1). Table 1 also includes a baseline case and the input parameters. The baseline case assumed that the cutters were fabricated from AISI 1095 steel and made use of properties obtained from a commercial material selection software package [14].

\section{TABLE 1 Material attributes and operating parameters used to model abrasive wear of rotary} shear cutter surfaces

\begin{tabular}{|c|c|c|c|c|}
\hline Attribute/Parameter & & Comments & $\begin{array}{l}\text { Input or } \\
\text { Output }\end{array}$ & Baseline \\
\hline Inorganic particle size $(\mathrm{m})$ & D & Particles assumed spherical for purposes of estimating particle density & Input & $1.00 \mathrm{E}-04$ \\
\hline Particle shape Factor & $\eta$ & Shape factor - multiplier used to scale effective diameter for purposes of calculating indentation depth - $h$ & Input & 1 \\
\hline Wear Constant & K & Wear constant - used to account for material that is deformed/moved but not physically removed from the surface & Input & 1 \\
\hline Particle Density $\left(\mathrm{kg} / \mathrm{m}^{3}\right)$ & $\rho_{\text {ash }}$ & Density of the particles $\left(\mathrm{kg} / \mathrm{m}^{3}\right)$ of the inorganic species - assumed to be silica & Input & 2600 \\
\hline Ash Content (wt \%) & $\mathrm{AC}(\%)$ & Percent ash content (wt\%) of inorganic mineral content & Input & 1 \\
\hline Biomass Density $\left(\mathrm{kg} / \mathrm{m}^{3}\right)$ & $\rho_{\text {biomass }}$ & Density of the organic (e.g. pine) species $\left(\mathrm{kg} / \mathrm{m}^{3}\right)$ & Input & 600 \\
\hline Biomass Chip Size $(\mathrm{m})$ & $D_{\text {biomass }}$ & Size of biomass chips - assumed spherical & Input & 0.02 \\
\hline Applied Pressure (Pa) & $\sigma$ & Effective presssure applied by biomass chips to cutter surfaces & Input & $2.00 \mathrm{E}+08$ \\
\hline Hardness $(\mathrm{Pa})$ of Biomass & $\mathrm{H}$ & Hardness of biomass $(\mathrm{Pa})$ & Input & $4.00 \mathrm{E}+07$ \\
\hline Feed rate $\left(\mathrm{kg}_{\text {biom }} / \mathrm{sec}\right)$ & FR & Feed rate of biomass into rotary shear unit $(\mathrm{kg} / \mathrm{sec})$ & Input & 0.25 \\
\hline Rotation Speed (rpm) & rpm & Rotary speed of shear cutters (rpm) & Input & 300 \\
\hline Cutter Rotation Speed (rads/sec) & $\omega$ & Rotary speed (Radians/sec) & Output & \\
\hline Cutting Angle (rads) & $\Delta \theta$ & Angle of inclusion - $2 \theta$ figure 8 & Output & \\
\hline Residence Time (sec) & $\tau$ & Time for a particle to transit through the shear zone & Output & \\
\hline Cutter width $(\mathrm{m})$ & $0.25 "$ & Width of cutters & Input & $0.25 "$ \\
\hline Cutter-Bearing Separation (m) & $0.375 "$ & Radial distance between the inner bearing and outer diameter of adjacent cutter & Input & $0.375 "$ \\
\hline Assembly Length $(\mathrm{m})$ & 24" & Overall length of cutter assembly - used to calculate cutter-bearing volume and particle density & Input & $24 "$ \\
\hline Cutter-Bearing Volume $\left(\mathrm{m}^{3}\right)$ & $\Delta v$ & Volume of active shear zome - used to calculate ash density & Output & \\
\hline Rotations per day (revs) & $\mathbf{N}$ & Number of revolutions per day @ full time operation & Output & \\
\hline Avg. ash conc $\left(\mathrm{kg}\right.$ ash $\left./ \mathrm{m}^{3}\right)$ & & Avg Conc $=\mathrm{FR}^{*} \mathrm{AC} \mathrm{C}^{*} \mathrm{\tau} / \Delta \mathrm{v}$ - used to calculate $\boldsymbol{X}$ & Output & \\
\hline Particles per $\mathrm{kg}_{\text {ash }}\left(\# / \mathrm{kg}_{\text {ash }}\right)$ & & \# particle $/ \mathrm{kgash}=1 /\left[(4 \pi / 3)(\mathrm{D} / 2)^{3} * \rho_{\text {part }}\right]$ - used to calculate $\mathbf{X}$ & Output & \\
\hline Particles per $\mathrm{m} 3\left(\# / \mathrm{m}^{3}\right)$ & & \# particles $/ \mathrm{m} 3=\left(\# \mathrm{~kg}\right.$ ash $\left./ \mathrm{m}^{3}\right) *$ (\# particle $\left./ \mathrm{kg}_{\text {ash }}\right)$ - used to caculate $\boldsymbol{X}$ & Output & \\
\hline Particles per unit area $\left(\# / \mathrm{m}^{2}\right)$ & $x$ & $\boldsymbol{X}$ density of inorganic particles residing on cutter surface & Output & \\
\hline Particle Hardness (GPa) & & Hardness of inorganic particles & Input & 9.8 \\
\hline Particle Young's Modulus (GPa) & & Young's modulus & Input & 73 \\
\hline Particle Poisson's Ratio & & Poisson's ratio & Input & 0.15 \\
\hline Particle kp & & Mean contact pressure factor & Input & 0.4 \\
\hline Biomass Hardness (GPa) & & Hardness of biomass & Input & 0.039 \\
\hline Biomass Young's Modulus (GPa) & & Young's modulus & Input & 14 \\
\hline Biomass Poisson's Ratio & & Poisson's ratio & Input & 0.38 \\
\hline Biomass kp & & Mean contact pressure factor & Input & 0.4 \\
\hline Cutter Hardness (GPa) & & Hardness of cutter & Input & 3.7 \\
\hline Cutter Young's Modulus (GPa) & & Young's modulus & Input & 212 \\
\hline Cutter Poisson's Ratio & & Poisson's ratio & Input & 0.28 \\
\hline Cutter kp & & Mean contact pressure factor & Input & 0.4 \\
\hline
\end{tabular}


Examples of the application of the model and the sensitivity to the input parameters are presented below. The calculations were all run assuming the particles were of the same size (e.g., $50 \mu \mathrm{m}, 100 \mu \mathrm{m}$ ).

1. The first set of comparisons demonstrates the impact of ash content and particle size on the predicted wear. Calculations were performed with the following assumptions: $1 \%$ and $10 \%$ ash content, and $50-\mu \mathrm{m}$ and $100-\mu \mathrm{m}$ particle sizes. For the initial runs, the shape factor was set to 1, as was the wear constant. The particle densities for these assumptions, along with calculations of the nominal load experinced by each particle, are presented in Table 2.

TABLE 2 Calculated particle densities for different particle sizes and ash content.

\begin{tabular}{|c|c|c|l|c|c|c|}
\hline & \multicolumn{2}{|c|}{$\mathrm{X}($ Particles/m2) } & & & \multicolumn{2}{c|}{ Load (N/particle) } \\
\hline $\mathbf{A C}(\%)$ & $\mathbf{5 0} \boldsymbol{\mu m}$ & $\mathbf{1 0 0} \boldsymbol{\mu m}$ & & $\mathbf{A C}(\%)$ & $\mathbf{5 0} \boldsymbol{\mu m}$ & $\mathbf{1 0 0} \boldsymbol{\mu m}$ \\
\hline $\mathbf{1}$ & $1.32 \mathrm{E}+06$ & $3.31 \mathrm{E}+05$ & & 1 & $7.70 \mathrm{E}-02$ & $3.08 \mathrm{E}-01$ \\
\hline $\mathbf{1 0}$ & $6.14 \mathrm{E}+06$ & $1.54 \mathrm{E}+06$ & & 10 & $7.70 \mathrm{E}-02$ & $3.08 \mathrm{E}-01$ \\
\hline
\end{tabular}

2. The second set of examples will illustrate the impact of particle shape (shape factor) and wear constant (fraction of material "scratched" that remains attached).

3. The third example will demonstrate the impact of hardness on the wear behavior. A comparison of the Rc 501095 steel will be compared against an iron-borided surface.

\subsection{Case 1 - Impact of Ash Content and Particle Size}

In this study, the impact of feedstock variability was examined through two types of [1\% and $10 \%$ ] ash content and two sizes of ash particles. The levels of ash content and particle sizes are given in Table 2. Results of the simulation are presented in Figure 14, where it can be seen that reducing the particle size from 100 to $50 \mu \mathrm{m}$ increases wear due to an increase in particle density (see Table 2). Increasing the ash content but keeping particle size constant also increases wear, again attributed to an increase in particle density (Table 2).

It should be noted that the magnitude of wear predicted from the model overestimates what is observed experimentally. More detailed measurements would be beneficial to "calibrate" the predictions, especially wear/recession measurements as a function of the quantity of biomass (and ash) processed. The results presented above also assume that the particles are spherical and that all material that is "scratched" is removed; in reality, the actual quantity of material removed is considerably less than 1 , with values closer to between 0.05 and 0.15 being reported [12]. The results presented in Case 2 examine the effects of nonspherical shapes and material retention more closely. 

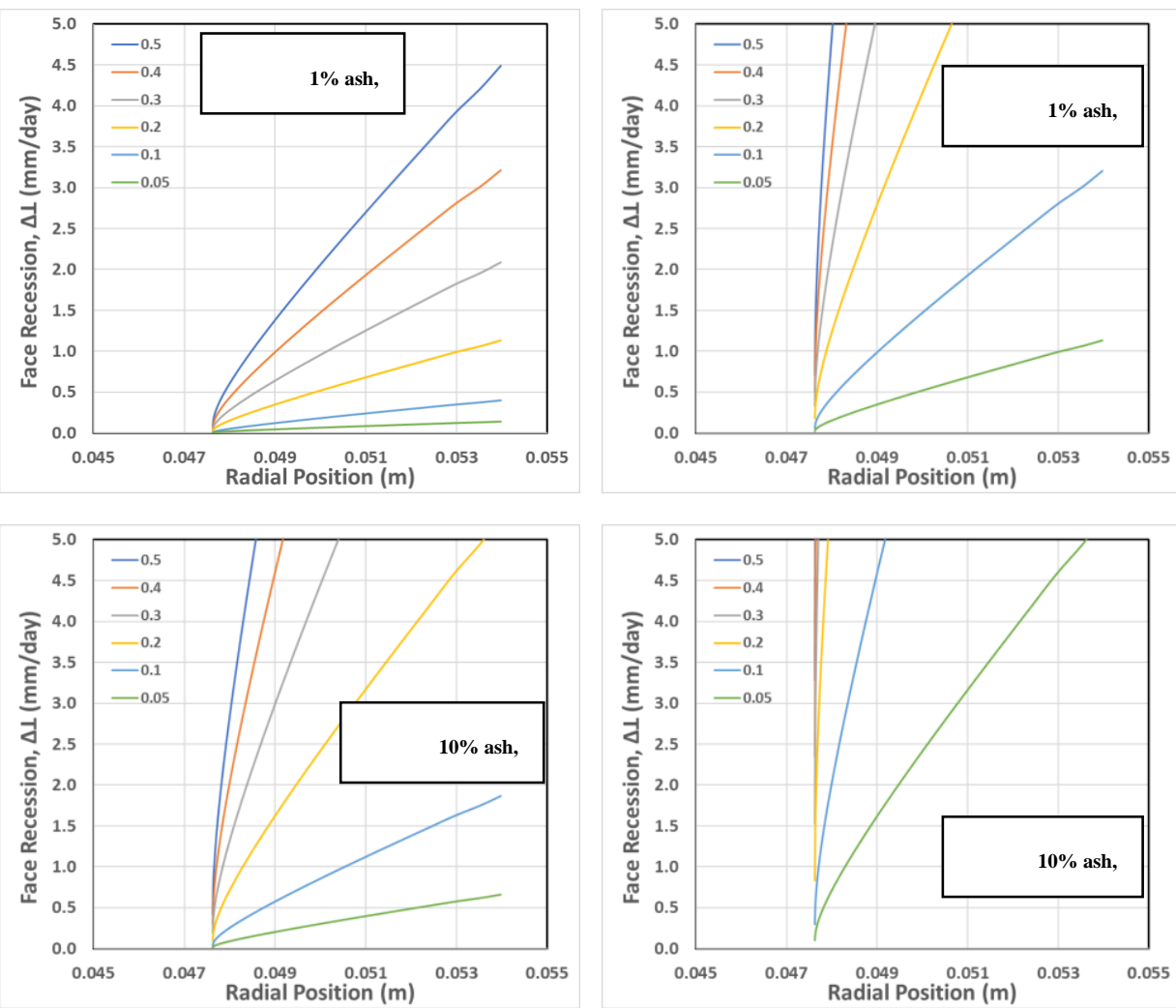

FIGURE 14 Predicted face recession after 1-day (24-hr) operation as a function of radial position for different levels of ash content and particle size.

\subsection{Case 2 - Impact of Particle Shape and Wear Constant}

The effects of nonspherical particle shapes and retention of scratched material on predicted wear recession are presented below. The rationale for incorporating a nonspherical shape can be justified experimentally. Most inorganic particles are nonspherical and quite often exhibit ellipsoidal/oval shapes as illustrated in Figure 15, which illustrates an oval particle "trapped" between two surfaces. The orientation shown with the "flatter" face of the particle positioned adjacent to the surfaces is an energetically more

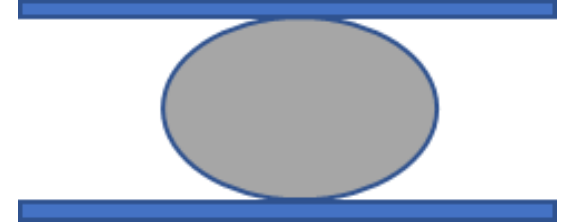

FIGURE 15 Simple illustration of an oval particle trapped between two surfaces. stable position, and thus the concept introduced in this study applies a shape factor that mathematically increases the diameter for calculating the indentation depth.

Figure 16 presents simulation results, which show the baseline case for an oval particle $(\eta=2)$ compared to the baseline spherical case $(\eta=1)$. The calculations indicate that an oval shape will reduce the wear/recession - in this case by a factor of 2 . 

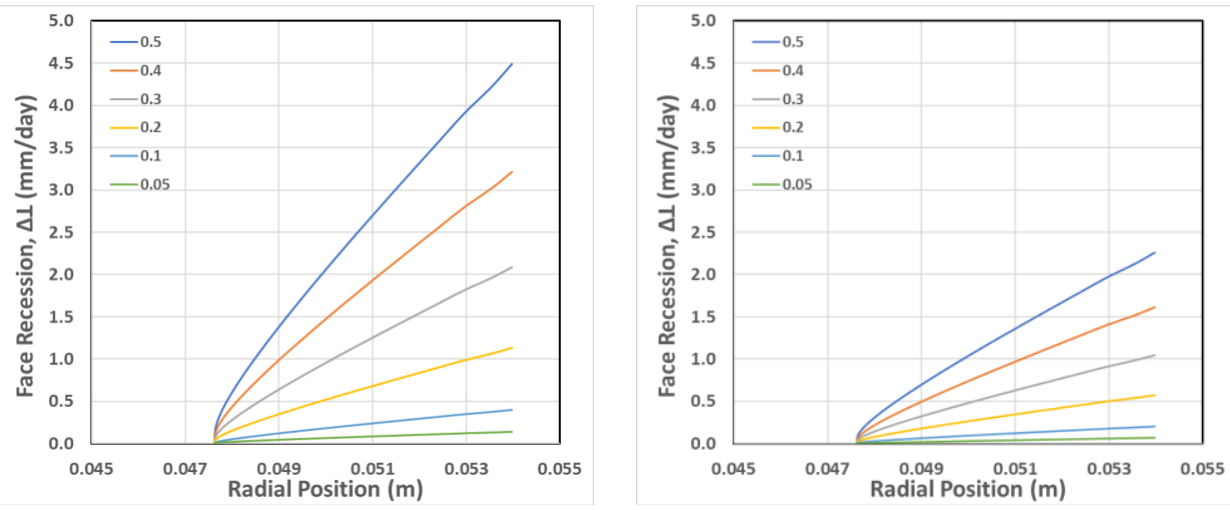

FIGURE 16 Edge recession as a function of radial position after 1-day (24-hr) operation for spherical particles (left, $\eta=1$ ) and oval particles (right, $\eta=2$ ).

The effect of incorporating a wear constant is illustrated in Figure 17, where the predicted edge recession is shown for a baseline case $(K=1)$, and one where $K=0.1$. Both the wear volume and edge recession are reduced in proportion to $K$. Figure 18 shows the effects of changing both the shape factor and wear constant.
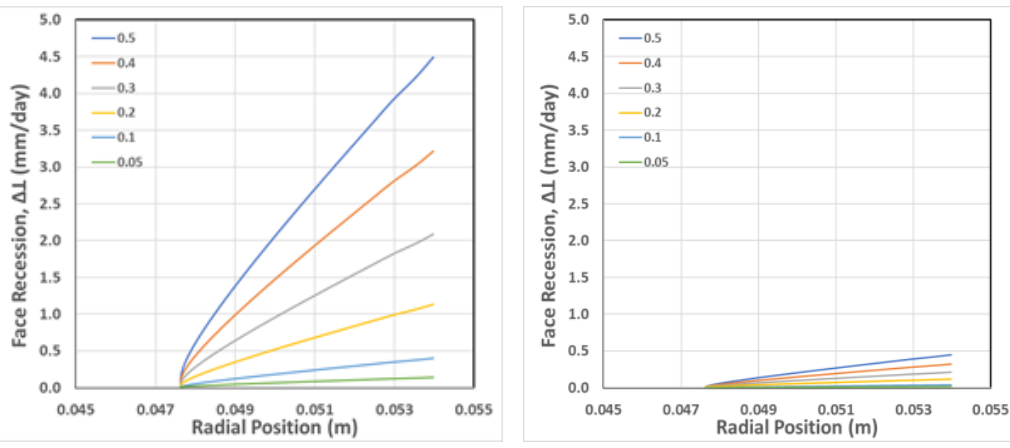

FIGURE 17 Edge recession as a function of radial position after 1-day (24-hr) operation for $\eta=1, K=1$ (left), and $\eta=1$, $\mathrm{K}=\mathbf{0 . 1}$ (right).
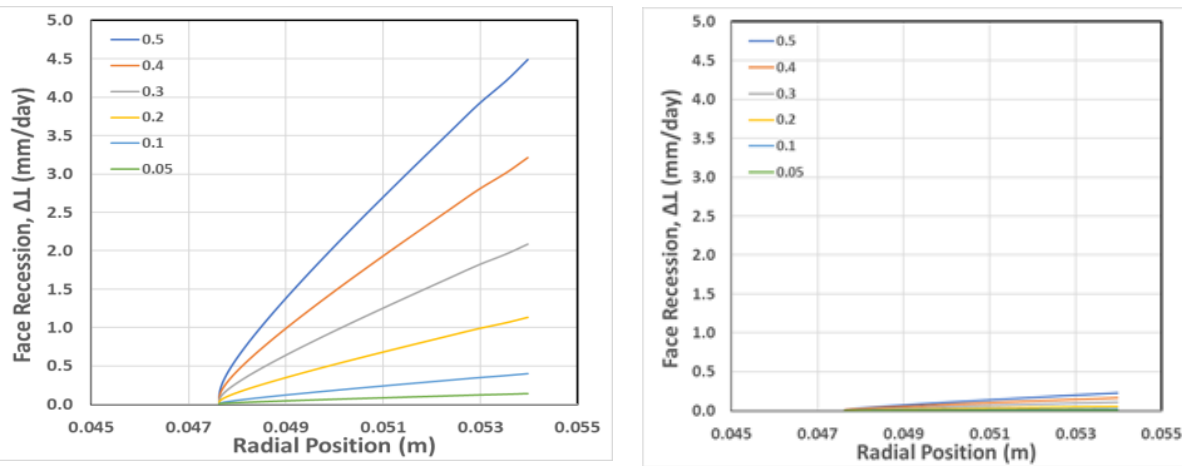

FIGURE 18 Edge recession as a function of radial position after 1-day (24-hr) operation for baseline $(\eta=1, K=1$, left) and modified $(\eta=2, K=0.1$, right). 


\subsection{Case 3 - Impact of Material Property (Hardness)}

This last case examines the impact of materials on wear/recession of the cutters. The baseline case is for cutters fabricated from AISI 1095 steel hardened to Rc50 (Hv 500). Three cases are considered: one that uses the baseline steel hardened to Rc50; a second using the same steel alloy but that is heat treated differently to $\mathrm{Hv} 650$; and a third case for an iron-borided steel whose near-surface hardness is $1800 \mathrm{Hv}$.

Results in Figure 19 show predicted edge recession for hardnesses of 500 (left), 650 (center), and $1500 \mathrm{Hv}$ (center). The results are as we would expect: harder materials will not wear as much as softer materials assuming hardness is the only factor affecting wear. Surface fatigue and toughness will also have an impact; however, for our present purposes, only the effect of hardness was considered. A final case is shown in Figure 20, which illustrates the impact of combining the effects of particle shape $(\eta=2)$, wear constant $(K=0.1)$, and hardness $(\mathrm{H}=1800)$. Note the change in scale for the combined case $(2,0.1,1800)$ vs. the base case $(1,1$, $500)$.
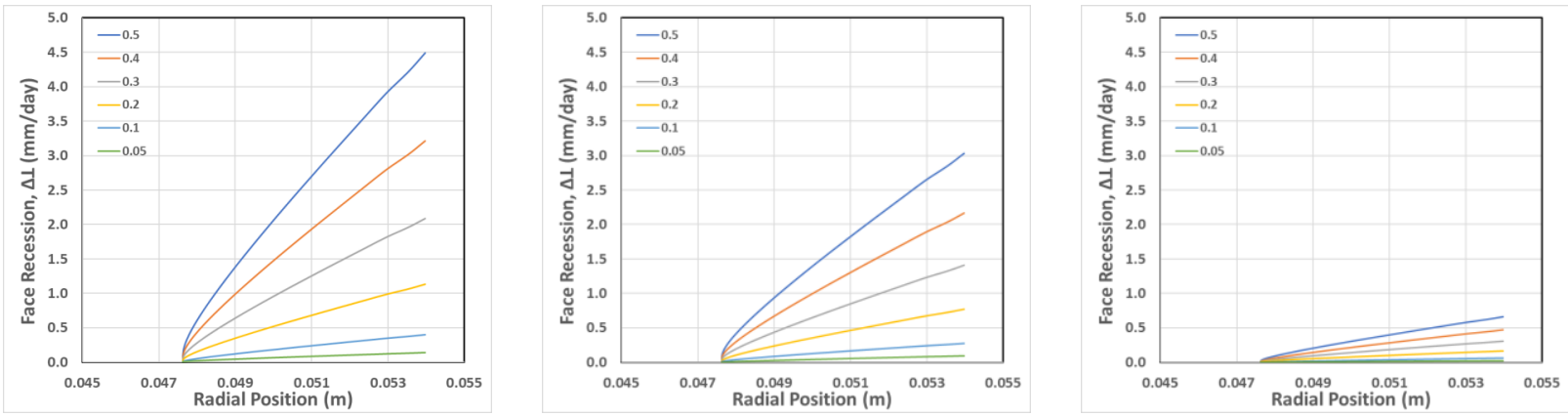

FIGURE 19 Edge recession as a function of radial position after 1-day (24-hr) operation ( $\eta=1$, $\mathrm{K}=1$ ) for baseline $(500 \mathrm{Hv}$, left), baseline heat treated to $\mathrm{Hv}=650$ (center), and iron borided $(\mathrm{Hv}=1800$, right $)$. 

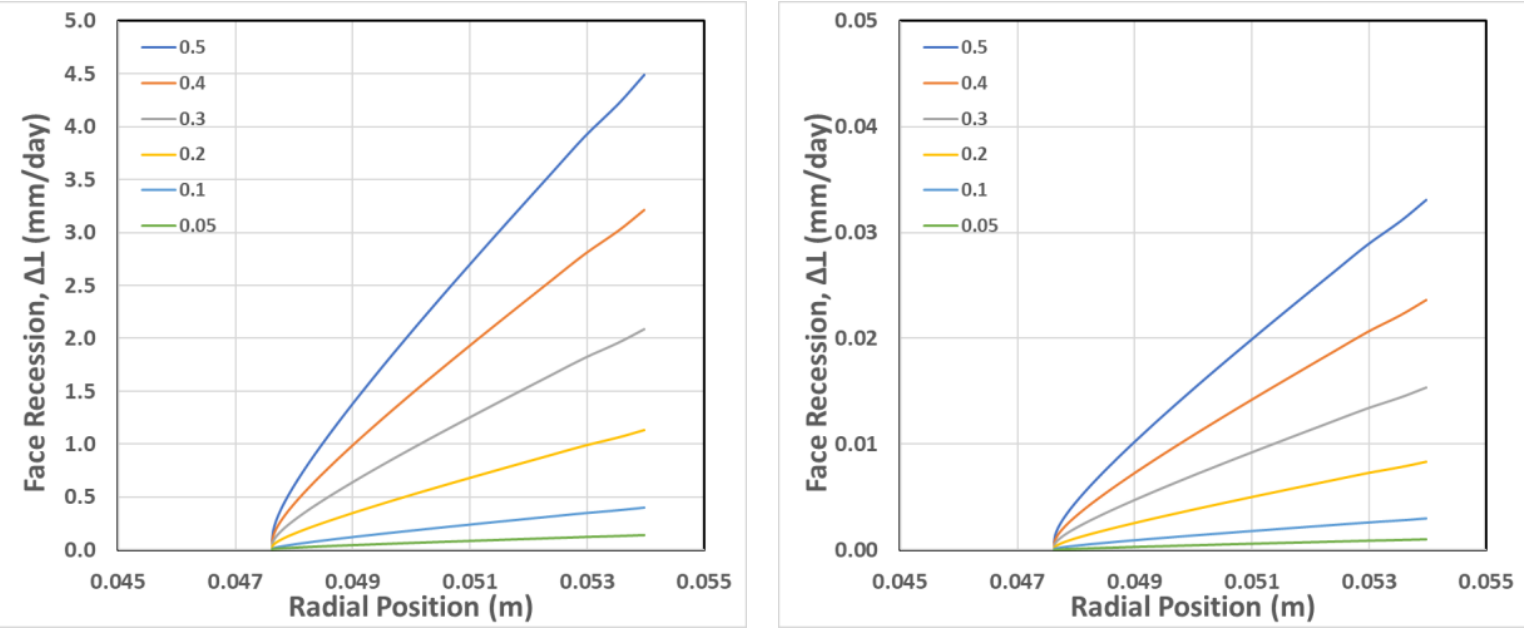

FIGURE 20 Comparison of predicted recession as a function of radial position after 24 hours running at $300 \mathrm{rpm}$ for baseline $(\eta=1, K=1, H v=500$, left) and combined run $(\eta=2, K=0.1$, $\mathrm{Hv}=1800$, right). Note the change in scale of the vertical axis for the figure on the right. 


\section{CONCLUSION}

We developed an analytical model from first principles and implemented it to predict abrasive wear on rotary shear cutters such as those used in the Forest Concept Crumbler®. Several cases evaluated the ability of the model to capture the impact of feedstock variability (ash size, ash content, and ash shape, i.e., oval vs. spherical, and moisture content through moisture-hardness correlations), process parameters (speed), and material attributes (cutter hardness).

Along with applying due diligence, the analytical model can serve as the basis for developing a QbD approach to guide optimization of rotary shear geometries (size and cutter thickness), operating conditions, and construction materials and to schedule maintenance outages based on operating history.

Future opportunities include the following:

- Integration of the model with FEM (finite element modeling) calculations of applied particle loads.

- Validation of the abrasive model against benchscale and field tests including, but not limited to, tracking of wear as a function of material/ash processed.

- Application of the model to predict wear on rotary shear clearance plates (kinematical analysis of motion between sheared debris and clearance plates). 


\section{REFERENCES}

[1] Office of Energy and Efficiency \& Renewable Energy, 2020, "Bioenergy Technologies." Available at https://www.energy.gov/eere/bioenergy.

[2] Julie Baruah, Bikash Kar Nath, Ritika Sharma, Sachin Kumar, Ramesh Chandra Deka, Deben Chandra Baruah, and Eeshan Kalita, 2018, "Recent Trends in the Pretreatment of Lignocellulosic Biomass for Value-Added Products," Frontiers in Energy Research 6, article 141. Available at www.frontiersin.org.

[3] Adepu Kiran Kumar and Shaishav Sharma, 2017, "Recent Updates on Different Methods of Pretreatment of Lignocellulosic Feedstocks: A Review," Bioresources and Bioprocessing 4, article 7. DOI 10.1186/s40643-017-0137-9.

[4] Solange Mussatto, ed., 2016, Biomass Fractionation Technologies for a Lignocellulosic Feedstock-Based Biorefinery, Elsevier. ISBN: 978-0-12-802323-5.

[5] Edward Wolfrum, "Feedstock Conversion Interface Consortium - Annual Review of Research - FY2020," report to DOE/EERE/BETO - in-preparation.

[6] Kyungjun Lee, Sougata Roy, Ercan Cakmak, Jeffrey A. Lacey, Thomas R. Watkins, Harry M. Meyer, Vicki S. Thompson, James R. Keiser, and Jun Qu, 2020, "CompositionPreserving Extraction and Characterization of Biomass Extrinsic and Intrinsic Inorganic Compounds,” ACS Sustainable Chem. Eng., 8, 1599-1610.

[7] George Fenske and Oyelayo Ajayi, 2020, "Identification of Critical Process Parameters for Knife Milling and Alternative Comminution Strategies," Argonne National Laboratory, ANL/AMD-20/3, December (released for distribution through OSTI.gov).

[8] https://forestconcepts.com/forest-concepts-awarded-doe-funding-to-model-biomassbehaviors-and-downstream-conversion-effects/.

[9] Jun Qu, Kyungjun Lee, Lianshan Lin, Jim Keiser, and Harry Meyer [Oak Ridge National Laboratory]; George Fenske and Layo Ajayi [Argonne]; and Dave Lanning [Forest Concepts], 2020, "FCIC DFO Project - Investigating and Addressing the Wear Issue of the Rotary Shear Biomass Comminution System," May 14.

[10] Jun Qu (Oak Ridge National Laboratory), private communication.

[11] Y. Zhao, D. Marietta, and L. Chang, 2000, "An Asperity Microcontact Model Incorporating the Transition From Elastic Deformation to Fully Plastic Flow," January, Transactions of the ASME.

[12] Y. Zhao and L. Chang, 2002, "A Micro-Contact and Wear Model for Chemical-Mechanical Polishing of Silicon Wafers," Wear, 252, 220-226. 
[13] https://mathworld.wolfram.com/CircularSegment.html.

[14] ANYSY Granta Selector - Materials Selection Software. Available at https://www.ansys.com/products/materials/granta-selector. 



\section{Argonne 4}

\section{Applied Materials Division}

Argonne National Laboratory

9700 South Cass Avenue, Bldg. 362

Lemont, IL 60439-4832

www.anl.gov 